\title{
Endoscopic submucosal dissection using countertraction with clips and rubber band allows safe en bloc resection of recurrent duodenal superficial lesions with intense fibrosis
}

Superficial duodenal epithelial neoplasia ( Fig. 1) can be endoscopically removed either with cold snare resection, conventional endoscopic mucosal resection (EMR) or endoscopic submucosal dissection (ESD). EMR is safe but can lead to a $20 \%-30 \%$ recurrence rate because of piecemeal resections. Conversely, duodenal ESD has a high rate of en bloc resection but is technically challenging and has $\leq 50 \%$ risk of complications (bleeding and perforation) [1,2].

We present the case of a 60-year-old patient with multiple sporadic duodenal adenomas. One of the lesions was particularly challenging because it was a recurrence after a previous EMR. Hybrid endoscopic resection was attempted but impossible due to severe submucosal fibrosis. We therefore performed ESD using the clip and rubber band traction technique ( Video 1 ) $[3,4]$. We closed the duodenal scar using clips and the patient was discharged after 48 hours of follow-up. The histology exam showed en bloc resection of a low-grade dysplastic duodenal adenoma and there were no complications after 3 weeks of follow-up. This is one of the first video cases showing ESD for duodenal recurrent lesions with severe fibrosis. As a full-thickness resection device for resection of upper digestive tract lesions is not yet approved in Europe, ESD using countertraction techniques can be an option for cases with intense fibrosis and high risk of perforation using conventional EMR.

Endoscopy_UCTN_Code_TTT_1AO_2AG

Competing interests

The authors declare that they have no conflicts of interest.
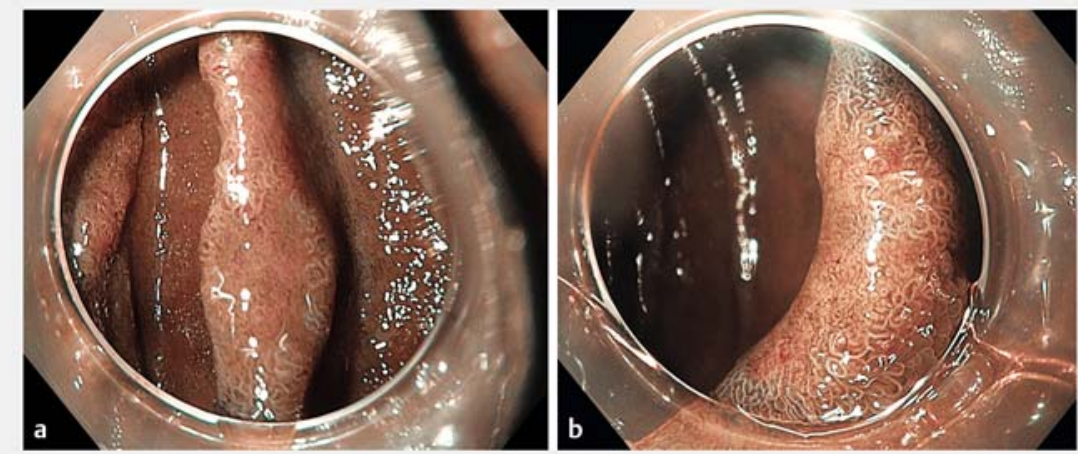

- Fig. 1 Duodenal adenomatous polyps. a Narrow-band imaging (NBI). b Dual-focus NBI.

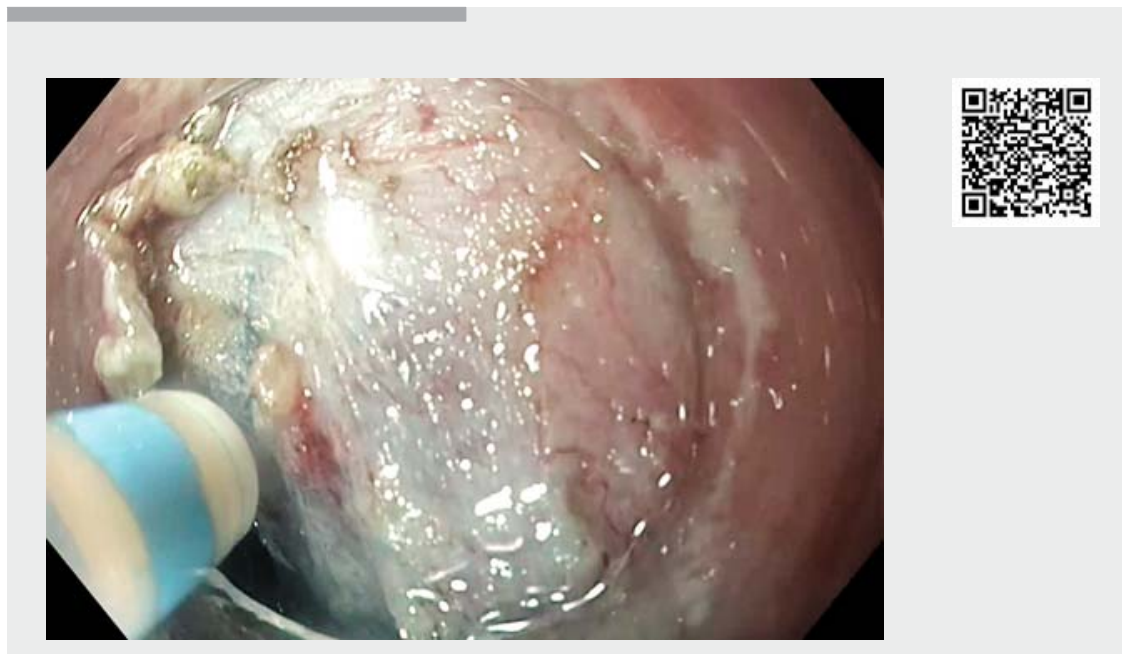

$\checkmark$ Video 1 Endoscopic submucosal dissection using countertraction for recurrent duodenal superficial lesions.

The authors

Alexandru Lupu ${ }^{1}$, Julien Faller ${ }^{1}$, Borathchakra Oung ${ }^{1}$, Timothée Wallenhorst ${ }^{2}$, Jérémie Jacques $^{3}$, Mathieu Pioche ${ }^{1}$

1 Endoscopy and Gastroenterology Unit, Edouard Herriot Hospital, Lyon, France

2 Department of Hepato-Gastroenterology, University Hospital of Pontchaillou, Rennes, France

3 Department of Endoscopy and Gastroenterology, Dupuytren University Hospital, Limoges, France
Corresponding author

\section{Alexandru Lupu, MD}

Endoscopy Unit - Digestive Disease Department, Pavillon L - Edouard Herriot Hospital, 5 Place Arsonval, 69437 Lyon Cedex, France

Fax: +33-4-72110147

alexandru.lupu@chu-lyon.fr 


\section{References}

[1] Yahagi N, Kato M, Ocihai Y et al. Outcomes of endoscopic resection for superficial duodenal epithelial neoplasia. Gastrointest Endosc 2018; 88: 676-682

[2] Kato M, Sasaki M, Mizutani M et al. Predictors of technical difficulty with duodenal ESD. Endosc Int Open 2019; 07: E1755E1760

[3] Jacques ], Charissoux A, Bordillon P et al. High proficiency of colonic endoscopic submucosal dissection in Europe thanks to countertraction strategy using a double clip and rubber band. Endosc Int Open 2019; 9: E1166-E1174
[4] Faller J, Jacques ], Oung B et al. Endoscopic submucosal dissection with double clip and rubber band traction for residual or locally recurrent colonic lesions after previous endoscopic mucosal re-section. Endoscopy 2020. doi:10.1055/a-1104-5210

\section{Bibliography}

Endoscopy 2020; 52: E398-E399

DOI 10.1055/a-1144-2611

ISSN 0013-726X

published online 17.4 .2020

(c) 2020. Thieme. All rights reserved.

Georg Thieme Verlag KG, Rüdigerstraße 14,

70469 Stuttgart, Germany

\section{ENDOSCOPY E-VIDEOS}

https:/|eref.thieme.de/e-videos

口局 Endoscopy E-Videos is a free access online section, reporting 回: on interesting cases and new techniques in gastroenterological endoscopy. All papers include a high quality video and all contributions are freely accessible online.

This section has its own submission website at https://mc.manuscriptcentral.com/e-videos 